\title{
DICOM Terminology
}

National Cancer Institute

\section{Source}

National Cancer Institute. DICOM Terminology. NCI Thesaurus. Code C69186.

A set of standard terms for communications regarding medical imaging. 